\title{
Risk Factors for Esophageal Fistula in Esophageal Cancer Patients Treated with Radiotherapy: A Systematic Review and Meta-Analysis
}

\author{
Chao Zhu ${ }^{a}$ Songping Wang ${ }^{a} \quad$ Yunhong You $^{a} \quad K^{2}$ eke Nie ${ }^{a}$ Youxin Jib \\ ${ }^{a}$ Department of Oncology, Qingdao Cancer Hospital, Qingdao, China; ${ }^{\mathrm{b}}$ Department of Oncology, The Affiliated \\ Qingdao Central Hospital of Qingdao University, Qingdao, China
}

\section{Keywords}

Risk factors · Esophageal fistula · Radiotherapy •

Meta-analysis

\begin{abstract}
Objective: Esophageal fistula is a critical and fatal complication of esophageal cancer. The aim of this meta-analysis was to explore the risk factors for esophageal perforation in esophageal cancer patients treated with radiotherapy. Methods: Data from the PubMed and Embase databases were retrieved for clinical research published between 1990 and 2018. The Newcastle-Ottawa Scale was used to evaluate the quality of the articles. A meta-analysis was performed using the RevMan 5.3 software provided by the Cochrane Collaboration Network. Results: Seventeen articles were eligible for the meta-analysis. In these articles, over 35 risk factors for esophageal fistula formation were described and 17 risk factors were analyzed. Significant differences in the odds of developing an esophageal perforation were found with regard to age (OR 2.34, 95\% Cl 1.08-5.03, $p=0.001)$, ulcerative type (OR 2.72, 95\% Cl 1.43-5.16, $p=0.002$ ), histology (OR $4.16,95 \% \mathrm{Cl} 1.14-15.12, p=0.03)$, T stage (OR $2.66,95 \% \mathrm{Cl}$ $1.44-4.91, p=0.002)$, short-term response (OR $2.21,95 \% \mathrm{Cl}$ $1.06-4.62, p=0.03$ ), chemotherapy regimen (OR 2.80, 95\% Cl $1.38-5.68, p=0.005)$, and stenosis (OR 2.00, 95\% Cl $1.03-$ $3.89, p=0.04)$. Conclusions: An age of $<60-65$ years, ulcerative type, squamous cell cancer, T4 stage, incomplete response, fluorouracil-based regimen, and stenosis were associated with an increased risk of esophageal fistula during or
\end{abstract} ation. diotherapy is around $5.6-33 \%$ [4-17]. studies are needed to establish the validity of this associ-

(c) 2019 S. Karger AG, Basel

Esophageal cancer is one of the most common malignant tumors in China and its outcome is poor, even though extensive research has been conducted and treatment implemented [1]. The majority of patients have no opportunity for surgical resection because of the tumor's position or disease development, or they undergo comrehensive treatment based on radiation therapy [2]. Esophageal perforation is a disastrous complication of phageal cancer after radiotherapy or during radiothapy [3]. The incidence of esophageal perforation

The causes of esophageal fistula in esophageal cancer patients are complicated. Esophageal cancer may become perforating during natural development, mainly because of tumor invasion, thinning of the esophageal wall, and increased intraluminal pressure during swallowing or severe coughing [18]. Treatment of esophageal cancer such as radiotherapy, chemotherapy, and brachytherapy may also cause esophageal fistula, owing to the imbalance between tumor shrinkage and normal tissue repair [19]. The prognosis of esophageal perforation is poor and the death 
Table 1. Characteristics of the studies included in the meta-analysis

\begin{tabular}{|c|c|c|c|c|c|c|c|c|}
\hline First author & Year & Location & Study design & $\begin{array}{l}\text { Patients } \\
\text { (fistula/all), } n\end{array}$ & Treatment & $\begin{array}{l}\text { Period of } \\
\text { treatment }\end{array}$ & $\begin{array}{l}\text { Study } \\
\text { quality, } \\
\text { NOS score }\end{array}$ & Ref. \\
\hline Zhang & 2018 & China & Prospective & $22 / 212$ & Chemoradiotherapy & 2014-2016 & 6 & {$[5]$} \\
\hline Tsushima & 2016 & Japan & Retrospective & $31 / 140$ & Chemoradiotherapy & 2004-2009 & 6 & {$[10]$} \\
\hline Chen & 2014 & China & Retrospective & $18 / 322$ & Chemoradiotherapy/radiotherapy & 2007-2011 & 6 & {$[14]$} \\
\hline Kawakami & 2018 & Japan & Retrospective & $28 / 116$ & Chemoradiotherapy & 2004-2015 & 6 & {$[15]$} \\
\hline Lingrong & 2018 & China & Retrospective & $22 / 336$ & Chemoradiotherapy/radiotherapy & 2012-2015 & 7 & {$[6]$} \\
\hline Kim & 2018 & Japan & Retrospective & $4 / 62$ & Chemoradiotherapy/radiotherapy & $2001-2015$ & 7 & {$[4]$} \\
\hline Kim & 2012 & Japan & Retrospective & $3 / 10$ & Chemoradiotherapy/radiotherapy & 2007-2011 & 5 & {$[11]$} \\
\hline Zhou & 2015 & China & Retrospective & $11 / 55$ & Radiotherapy & 2003-2012 & 5 & {$[13]$} \\
\hline Yamaguchi & 2011 & Japan & Retrospective & $4 / 31$ & Chemoradiotherapy/radiotherapy & 1996-2008 & 7 & {$[17]$} \\
\hline Gaspar & 2000 & America & Prospective & $6 / 49$ & $\begin{array}{l}\text { Chemoradiotherapy/radiotherapy/ } \\
\text { brachytherapy }\end{array}$ & 1992-1995 & 5 & [7] \\
\hline Taal & 1996 & The Netherlands & Prospective & $6 / 74$ & Radiotherapy/brachytherapy & 1991-1994 & 5 & [9] \\
\hline Sun & 2016 & China & Retrospective & $17 / 179$ & Chemoradiotherapy & 2009-2014 & 8 & {$[8]$} \\
\hline Hama & 2002 & Japan & Retrospective & $3 / 6$ & Radiotherapy/brachytherapy & 1996-1997 & 4 & {$[28]$} \\
\hline Ohtsu & 1999 & Japan & Prospective & $5 / 54$ & Chemoradiotherapy & 1992-1997 & 5 & {$[30]$} \\
\hline Kaneko & 2003 & Japan & Retrospective & $3 / 57$ & Chemoradiotherapy & 1996-2000 & 5 & {$[31]$} \\
\hline
\end{tabular}

rate is high [20]. Patients with esophageal perforation are prone to develop secondary uncontrolled mediastinitis or lung infection, which leads to systemic infection and even to toxic shock and death [21]. At present, there are no satisfactory treatments [22-24]; therefore, the prevention of esophageal fistula should be taken seriously. However, no definitive risk factors for esophageal perforation have been identified. We performed this meta-analysis to provide comprehensive and systematic data on the topic. To the best of our knowledge, this is the first meta-analysis of risk factors for esophageal fistula relevant to esophageal cancer patients on radiation therapy.

\section{Methods}

\section{Information Sources and Search Parameters}

A systemic bibliographic search on PubMed and Embase was performed using the terms "esophagus cancer [MeSH]" and "tracheoesophageal fistula," "esophagorespiratory fistula" or "esophageal fistula" or "esophageal perforation" and "radiotherapy" or "radiation therapy" or "chemoradiotherapy." A total of 779 articles published between 1990 and 2018 were found. After a thorough search, 120 duplicates were removed and the remaining articles were screened by title and abstract; thereafter, the full texts were examined as potential articles for analysis. A search through the references in the available articles was also conducted to retrieve missing articles.

\section{Eligibility Criteria and Exclusion Criteria}

Studies which met the following criteria were included: (1) all subjects were definitely diagnosed with esophageal cancer; (2) data regarding esophageal perforation or fistula were presented; and (3) all patients were treated with radiation therapy. Studies meeting the following criteria were excluded: (1) studies other than clinical trials (case reports, reviews, questionnaires, editorial notes, etc.);
(2) there were fewer than 3 cases of esophageal perforation; (3) studies failing to provide sufficient data; (4) articles neither in English nor in Chinese; and (5) studies related to postoperative complications of esophageal cancer or indistinguishable. The first author's name, country, year of publication, study type, clinical patient information, and risk factors for fistula were extracted from the articles for analysis (Table 1).

\section{Quality Assessment}

We used the Newcastle-Ottawa Quality Assessment Scale (NOS) [25] to evaluate the methodological quality of the eligible studies. The NOS checklist is applicable to case-control studies or cohort studies. The assessment was carried out regarding three aspects: subject choice (4 scores in total), comparability between groups ( 2 scores in total), and exposure assessment (3 scores in total). A score of more than 5 points is considered to represent high quality.

Two independent reviewers screened the retrieved articles, extracted the data, and evaluated the quality of the included studies. Discrepancies were settled by consensus or submitted to a third reviewer for assistance.

\section{Statistical Analysis}

The meta-analysis was conducted by synthesizing the outcomes of the studies in which potential risk factors for esophageal fistula were presented. Microsoft Excel was used for data entry and RevMan 5.3 was used for the meta-analysis. We used the MantelHaenszel method to calculate odds ratios (ORs) and 95\% confidence interval (CIs).

Heterogeneity was assessed by inconsistency statistics $\left(I^{2}\right)$ and the $\chi^{2}$ test [26]. $I^{2}$ values $<25 \%,<50 \%$, and $>50 \%$ were considered to represent low, moderate, and severe heterogeneity, respectively [26]. In the presence of low heterogeneity, the fixed-effects model was used to pool the primary outcomes. The random-effects model was utilized for the other two conditions. A $p$ value $<0.05$ indicated statistical significance. Assessment of publication bias was conducted by funnel plot when there were more than 10 studies [27]. The robustness and reliability of the pooled outcomes were assessed by sensitivity analysis. 


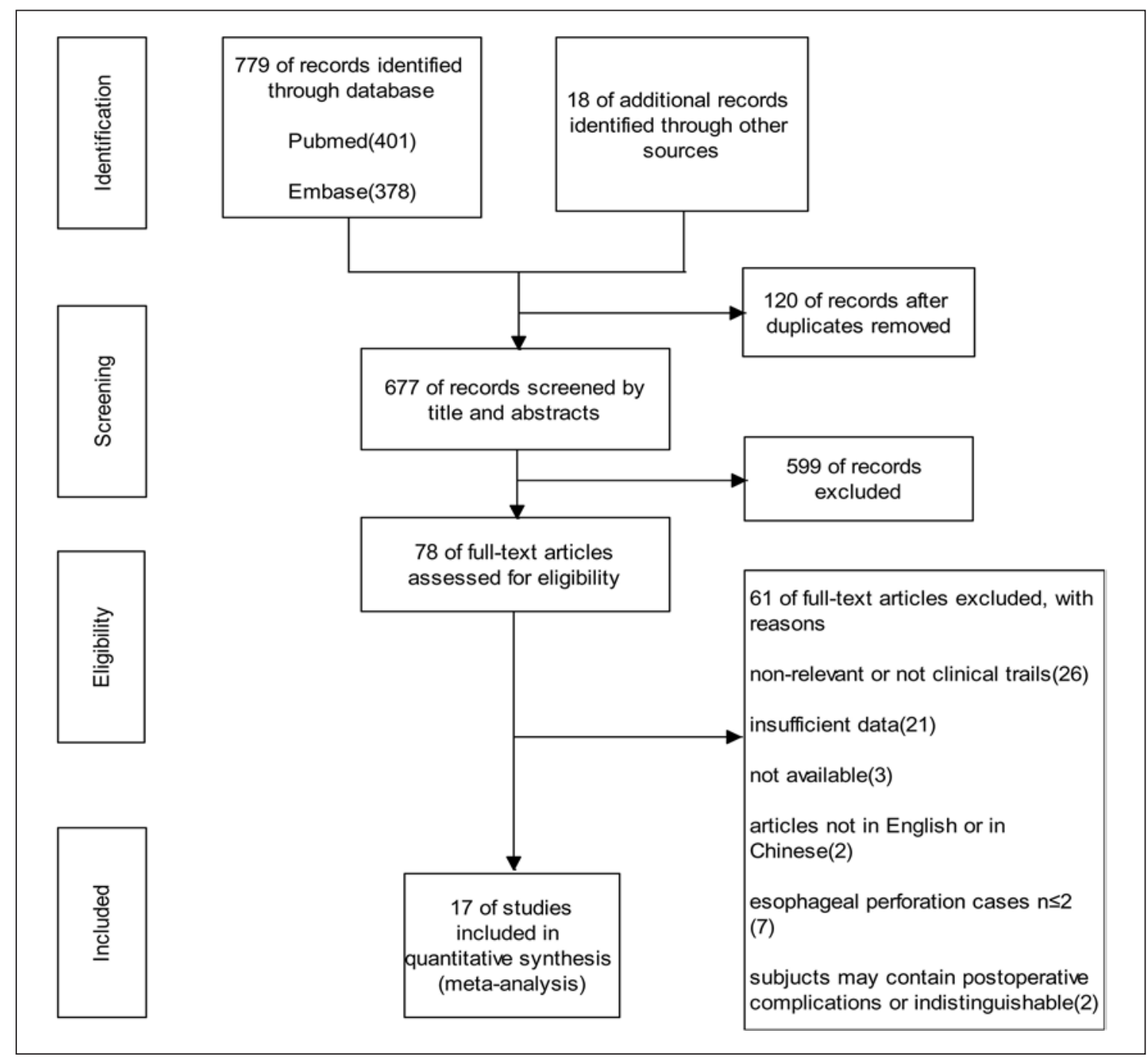

Fig. 1. Flowchart of the study selection process.

\section{Results}

\section{Study Selection and Characteristics of the Eligible Articles}

After data retrieval from the databases and eliminating duplicates, 677 articles were obtained. After reading the titles and abstracts, 599 articles were removed, and the remaining 78 studies were reviewed in full text. Based on the eligibility and exclusion criteria, a total of 17 studies, including 1,866 patients, were included in the meta-analysis (Fig. 1). The included studies consisted of 4 prospective studies and 13 retrospective studies. Fourteen of the studies were carried out in East Asian countries including China and Japan (82.4\%); 1 was carried out in the USA, 1 in Brazil, and 1 in the Netherlands. The sample size ranged from 6 to 322. The characteristics of the studies eligible for meta-analysis are shown in Table 1.

\section{Risk Factors}

In the 17 articles, over 35 risk factors for esophageal fistula formation were described. Meta-analyses were performed for those risk factors that were presented in more than one article (Fig. 2). The examined risk factors and relevant studies are listed in Table 2.

\section{Effect of Patient Status on Fistula Formation}

Gender

Eight articles [4-6, 10, 11, 14-16] reported on gender $(n=1,246)$. The meta-analysis demonstrated no difference between males and females in the risk of esophageal fistula (OR 1.31, 95\% CI $0.73-2.36, p=0.36$ ). Slight heterogeneity was found $\left(I^{2}=8 \%, p=0.37\right)$.

\section{Age}

Age was reported in 8 articles [4-6, 10, 11, 14-16], but 3 of them $[10,15,16]$ were excluded because of insufficient data. The meta-analysis found a significant differ- 
Fig. 2. Meta-analysis of the risk factors for esophageal fistula in esophageal cancer patients treated with radiotherapy.

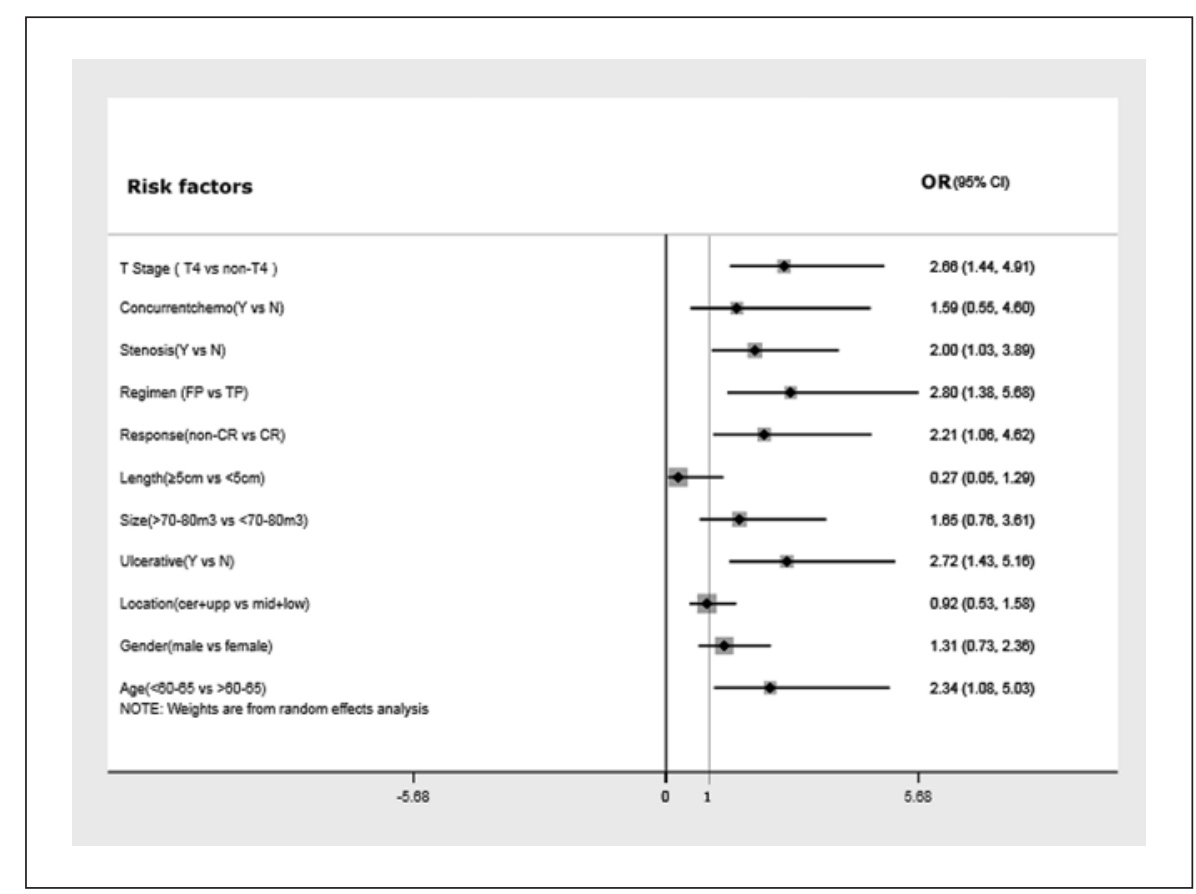

Table 2. Risk factors for esophageal fistula formation in esophageal cancer patients receiving radiotherapy

\begin{tabular}{llll}
\hline Patients' status [Ref.] & Tumor & Treatment & Others \\
\hline Gender $[4-6,10,11,14-16]$ & Ulcerative tumor $[5,8,10]$ & Concurrent chemoradiotherapy $[5,11,14,17]$ & Stenosis $[4,5,10,15]$ \\
Age $[4-6,11,14]$ & Tumor location $[5,9-11,16,28,29]$ & Treatment response $[4,6,9,11]$ & \\
KPS/PS $[5,10,11,14-16]$ & T4 $[4-8,10,11,14,30,31]$ & Chemotherapy regimen $[5,8]$ & \\
Albumin $[10,15]$ & Histology $[6,9]$ & Re-radiotherapy $[6,13,14]$ & \\
Hemoglobin $[10,15]$ & Tumor length $[15,16]$ & & \\
BMI $[5,16]$ & Tumor size $[7,28]$ & & \\
\hline
\end{tabular}

KPS, Karnofsky Performance Status; PS, performance status; BMI, body mass index.

ence between the group older than 60-65 years and the group younger than $60-65$ years. The patients younger than 60-65 years had a greater risk of developing esophageal fistula than the patients older than $60-65$ years (OR $2.34,95 \%$ CI $1.08-5.03, p=0.03)$. Moderate heterogeneity was found $\left(I^{2}=41 \%, p=0.15\right)$.

Karnofsky Performance Status/Performance Status

Six clinical studies $[5,10,11,14-16](n=526)$ examined the role of the Karnofsky Performance Status/performance status (KPS/PS) on fistula formation, and the meta-analysis showed no significant difference in the risk of developing esophageal fistula (OR 0.76, 95\% CI 0.30$1.93, p=0.56$ ). However, a remarkably high heterogeneity was found $\left(I^{2}=73 \%, p=0.002\right)$. A moderator analysis was carried out. After removal of the study by Chen et al. [14], a decrease in heterogeneity was found $\left(I^{2}=56 \%, p=0.06\right)$, but there still was no significant difference between groups (OR 1.09, 95\% CI 0.49-2.42, $p=0.84$ ).
Hemoglobin, Albumin, and Body Mass Index

Two articles reported on hemoglobin [10, 15], and there was no significant difference between patients with normal/high hemoglobin levels and patients with low hemoglobin levels (OR 2.21, 95\% CI 0.88-5.50, $p=0.09$; heterogeneity: $\left.I^{2}=47 \%, p=0.17\right)$. We also determined no effect of body mass index (BMI) $[5,16]$ (>20-24 vs. $<20-24$; OR $0.88,95 \%$ CI $0.33-2.36, p=0.80$; heterogeneity: $\left.I^{2}=56 \%, p=0.13\right)$ and albumin $[10,15]$ (>3.5 vs. $<3.5 \mathrm{~g} / \mathrm{dL}$; OR $0.46,95 \%$ CI $0.16-1.27, p=0.13$; heterogeneity: $I^{2}=36 \%, p=0.21$ ) on esophageal fistula formation. However, these results should be treated with caution owing to the small number of included studies.

\section{Tumor-Related Risk Factors}

Location

Seven studies [5, 9-11, 16, 28, 29] included this factor $(n=605)$. The meta-analysis demonstrated no significant difference between patients with cervical/upper disease and 
those with middle/lower disease with regard to the development of esophageal fistula (OR 0.92, 95\% CI 0.53-1.58, $p=0.75)$. No heterogeneity was found $\left(I^{2}=0 \%, p=0.96\right)$.

\section{T Stage}

This risk factor was examined in 10 articles $[4-8,10$, $11,14,30,31](n=1,291)$. Overall, a significant difference in the odds for the development of esophageal fistula was found (OR 2.66, 95\% CI 1.44-4.91, $p=0.002$ ). The patients with T4 disease were more likely to have a fistula than the patients with non-T4 disease. Heterogeneity was moderate $\left(I^{2}=30 \%, p=0.17\right)$. The funnel plot showed asymmetry, suggesting that publication bias may have existed (Fig. 3).

\section{Ulcerative Type}

The risk factor "ulcerative type" was discussed in 3 studies $[5,8,10](n=531)$. A significant difference in the odds for fistula formation was seen between patients with and those without ulcerative-type disease (OR 2.72, 95\% CI 1.43-5.16, $p=0.002$ ). The patients with ulcerative disease had a higher risk of developing esophageal fistula. No heterogeneity was found $\left(I^{2}=0 \%, p=0.41\right)$.

\section{Histology}

Two articles $[6,9](n=410)$ offered sufficient data on histology for a meta-analysis. Patients with squamous cell cancer had a higher risk of having esophageal fistula (OR $4.16,95 \%$ CI $1.14-15.12, p=0.03)$. Slight heterogeneity was found $\left(I^{2}=23 \%, p=0.25\right)$.

We also performed meta analyses to determine the effect of tumor size $[7,28]$ and tumor length $[15,16]$ on the risk of fistula formation. However, no statistically significant difference was found for tumor size (OR 1.65, 95\% CI $0.76-3.61, p=0.10$; heterogeneity: $I^{2}=0 \%, p=0.37$ ) and tumor length (OR $0.61,95 \%$ CI $0.28-1.32, p=0.21$; heterogeneity: $I^{2}=0 \%, p=0.62$ ).

\section{Tumor-Related Factors}

Short-Term Response

This risk factor was discussed in 4 articles $[4,6,9,11]$ $(n=482)$. Among patients without complete remission (CR), the probability of esophageal fistula formation was increased (OR 2.21, 95\% CI 1.06-4.62, $p=0.03$ ), and no heterogeneity could be observed $\left(I^{2}=0 \%, p=0.42\right)$.

\section{Chemotherapy Regimen}

A chemotherapy regimen with fluorouracil plus cisplatin (FP) versus taxane plus cisplatin (TP) was studied in 2 articles $[5,8](n=391)$. The meta-analysis showed that the odds for developing fistula among subjects undergoing the fluorouracil-plus-cisplatin regimen were higher than among those receiving the taxane-plus-cisplatin regimen (OR 2.80, 95\% CI 1.38-5.68, $p=0.005$ ).

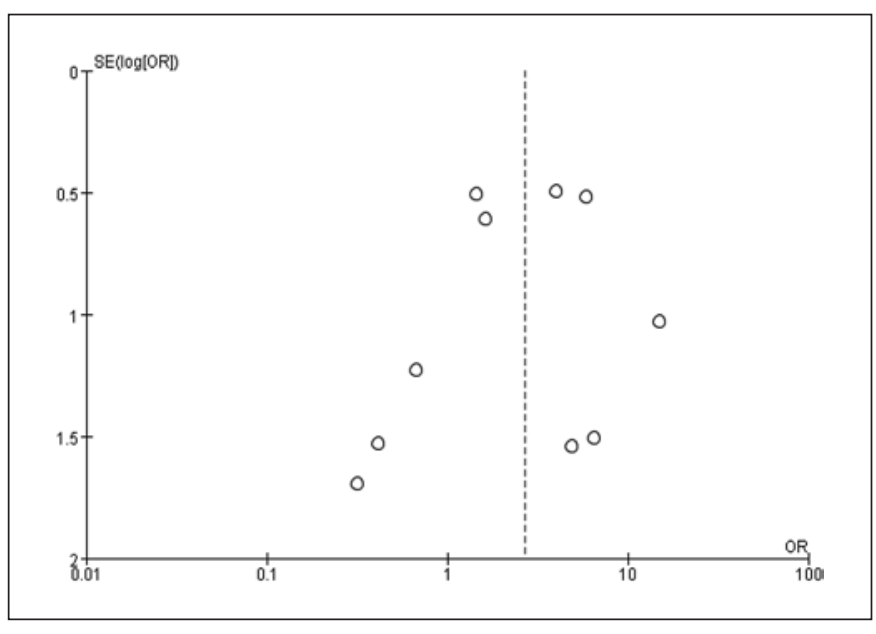

Fig. 3. Publication bias tested by funnel plot for T stage.

No heterogeneity was found $\left(I^{2}=0 \%, p=0.78\right)$. Due to the small number of cases, this result should be interpreted with caution.

Four articles reported on concurrent chemotherapy $[5,11,14,17](n=575)$. The meta-analysis did not lead to a significant difference between patients with and those without concurrent chemotherapy (OR 1.59, 95\% CI $0.55-4.80, p=0.40)$. Heterogeneity was high $\left(I^{2}=49 \%\right.$, $p=0.12)$. We performed a moderator analysis after removal of the study by Chen et al. [14]; no heterogeneity was found $\left(I^{2}=0 \%, p=0.74\right)$, nor did the analysis have an influence on the odds ratio (OR $0.95,95 \%$ CI $0.41-$ $2.19, p=0.9$ ).

Three articles $[6,13,14](n=772)$ presented sufficient data on re-radiation as a risk factor. No significant difference between groups was observed (OR 2.73, 95\% CI $0.65-11.52, p=0.17)$. High heterogeneity was observed $\left(I^{2}=68 \%, p=0.04\right)$. After removal of the study by Chen et al. [14], no heterogeneity was found $\left(I^{2}=0 \%, p=0.83\right)$, nor did the analysis have an influence on the odds ratio (OR 1.31, 95\% CI 0.52-3.31, $p=0.57$ ).

\section{Other Risk Factors}

\section{Stenosis}

Stenosis was reported as a factor in 4 articles $[4,5,10$, 15] ( $n=530)$. The meta-analysis showed that the odds for fistula formation were 2.00 times higher in the group with stenosis (OR 2.00, 95\% CI 1.03-3.89, $p=0.04$ ). Moderate heterogeneity was found $\left(I^{2}=34 \%, p=0.21\right)$.

\section{Discussion}

Esophageal perforation is one of the most serious complications of esophageal cancer; most patients will die of it within 3 months [20]. Therefore, the prevention of fis- 
tula formation is very important for an individualized cancer treatment. The purpose of this meta-analysis was to identify risk factors for esophageal perforation in esophageal cancer patients treated with radiotherapy.

A total of 17 articles reporting over 35 risk factors were included, and we carried out a meta-analysis for 17 risk factors. Seven of the 17 examined factors (age, ulcerative type, histology, T stage, short-term response, chemotherapy regimen, and stenosis) were related to the formation of esophageal perforation. The 10 remaining factors (gender, hemoglobin, KPS/PS, albumin, BMI, tumor location, tumor length, tumor size, re-radiotherapy, and concurrent chemoradiotherapy) had no significant correlation with esophageal fistula formation.

Our study showed that stenosis was a strong predictor of esophageal perforation; the odds for developing esophageal fistula were 2.00 times higher in this group. The mechanism of this phenomenon is not yet completely understood. It may be associated with food friction or increased intraesophageal pressure caused by swallowing and severe cough [5]. Clinicians should be alerted to the risk of esophageal perforation in patients with esophageal stenosis during or after radiotherapy. However, there is a limitation, since the diagnosis of stenosis was not performed according to the same standards in the different studies, or it was not clearly described. Thus, to unify the evaluation system for the diagnosis of stenosis with patients' symptoms and/ or imaging manifestations is quite important.

T4 stage is another significant prognostic factor. The risk of esophageal fistula in patients with stage $\mathrm{T} 4$ cancer is 2.66 times higher than that in T1-3 stage cancer patients. Anatomically, the esophagus is surrounded by the trachea, large vessels, and the lung. Cancer of the T4 stage means that tumor tissue infiltrates the whole layer of the esophagus into the surrounding tissues. It is easy for a fistula to form when the rate of tumor regression is faster than that of normal tissue repair. In addition, if the tumor is residual after treatment, esophageal perforation may occur if the disease progresses [6]. The risk of esophageal perforation in patients who did not reach CR after treatment was 2.21 times higher than that in CR patients.

Patients with the ulcerative type maybe have a higher risk of developing esophageal fistula. One of the reasons is that the injured mucosa is prone to fungal infection, which can affect the subepithelial venous plexus to cause mucous edema and circulatory disorder [32]. However, Tsushima et al. [10] insisted that ulcers should not be counted as a risk factor, because all ulcers will occur before perforation.

Esophageal perforation was more frequent with fluorouracil than with taxane administration. An explanation for this might be that fluorouracil increases the risk of mucositis, leading to a higher probability of perforation [33].
The patients younger than 60-65 years were found to have a higher risk of fistula formation. This may be owing to the more intensive treatment regimen used in this group, which may accelerate contraction of the tumor but inhibit repair of the normal tissue [14].

Whether re-radiation can increase the risk of perforation cannot be definitely determined. The salvage measures for esophageal cancer recurrence after radiotherapy are surgery, re-radiotherapy, chemotherapy, brachytherapy, and so on [34-36]. The data on re-radiation were scarce [37]. On the one hand, re-radiation can control the progression of local tumors; on the other hand, re-irradiation may cause more serious damage to the tissues damaged by radiotherapy [14]. The incidence of esophageal fistula among re-radiation patients was as high as $12-33 \%$ [11-13, 17]. However, no significant results have been obtained in our study.

There are several limitations to our study. Firstly, all the included studies came from published literature, which is why there is the possibility of publishing bias. Secondly, the majority of the subjects studied were East Asian, with relatively few Caucasians enrolled. Some indicators were reported in few studies; therefore, an effective subgroup analysis could not be carried out in the presence of heterogeneity, which may have had a certain impact on the results. Finally, for the risk factors of age, BMI, and KPS, the cutoffs were intervals, which is because the cutoffs provided in the literature were not uniform.

In conclusion, our study showed risk factors for esophageal fistula or perforation in patients with esophageal cancer undergoing radiotherapy. The factors age $<60-65$ years, ulcerative type, squamous cell cancer, T4 stage, non-CR, fluorouracil-based regimen, and stenosis were associated with an increased risk of esophageal fistula formation.

\section{Statement of Ethics}

The authors have no ethical conflicts to disclose.

\section{Disclosure Statement}

All authors declare no conflict of interest.

\section{References}

\footnotetext{
1 Siegel RL, Miller KD, Jemal A. Cancer statistics, 2018. CA Cancer J Clin. 2018 Jan;68(1): 7-30.

2 Sohda M, Kuwano H. Current Status and Future Prospects for Esophageal Cancer Treatment. Ann Thorac Cardiovasc Surg. 2017 Feb;23(1):1-11.

3 Chang CY, Chang YT, Lee PL, Lin JT. Tracheoesophageal fistula. Gastrointest Endosc. 2004 Jun;59(7):870.
} 
4 Kim JW, Kim TH, Kim JH, Lee IJ. Predictors of post-treatment stenosis in cervical esophageal cancer undergoing high-dose radiotherapy. World J Gastroenterol. 2018 Feb;24(7): 862-9.

5 Zhang Y, Li Z, Zhang W, Chen W, Song Y. Risk factors for esophageal fistula in patients with locally advanced esophageal carcinoma receiving chemoradiotherapy. Onco Targets Ther. 2018 Apr;11:2311-7.

6 Lingrong T, Guang LI. Clinical Analysis of Esophageal Perforation during or after Radiotherapy for Esophageal Carcinoma. Zhongguo Yike Daxue Xuebao. 2018;47(5):439-42.

7 Gaspar LE, Winter K, Kocha WI, Coia LR, Herskovic A, Graham M. A phase I/II study of external beam radiation, brachytherapy, and concurrent chemotherapy for patients with localized carcinoma of the esophagus (Radiation Therapy Oncology Group Study 9207): final report. Cancer. 2000 Mar;88(5): 988-95.

8 Sun X, Han S, Gu F, Lin G, Wang Z, Wang Y, et al. A retrospective comparison of taxane and fluorouracil-based chemoradiotherapy in patients with inoperable esophageal squamous cell carcinoma. J Cancer. 2016 May; 7(9):1066-73.

9 Taal BG, Aleman BM, Koning CC, Boot H. High dose rate brachytherapy before external beam irradiation in inoperable oesophageal cancer. Br J Cancer. 1996 Nov;74(9): 1452-7.

10 Tsushima T, Mizusawa J, Sudo K, Honma Y, Kato K, Igaki H, et al.; Japan Esophageal Oncology Group of Japan Clinical Oncology Group (JCOG). Risk Factors for Esophageal Fistula Associated with Chemoradiotherapy for Locally Advanced Unresectable Esophageal Cancer: A Supplementary Analysis of JCOG0303. Medicine (Baltimore). 2016 May; 95(20):e3699.

11 Kim YS, Lee CG, Kim KH, Kim T, Lee J, Cho $\mathrm{Y}$, et al. Re-irradiation of recurrent esophageal cancer after primary definitive radiotherapy. Radiat Oncol J. 2012 Dec;30(4):182-8.

12 Chen Y, Lu Y, Wang Y, Yang H, Xia Y, Chen $\mathrm{M}$, et al. Comparison of salvage chemoradiation versus salvage surgery for recurrent esophageal squamous cell carcinoma after definitive radiochemotherapy or radiotherapy alone. Dis Esophagus. 2014 Feb-Mar;27(2): $134-40$

13 Zhou ZG, Zhen CJ, Bai WW, Zhang P, Qiao $\mathrm{XY}$, Liang JL, et al. Salvage radiotherapy in patients with local recurrent esophageal cancer after radical radiochemotherapy. Radiat Oncol. 2015 Feb; 10:54

14 Chen HY, Ma XM, Ye M, Hou YL, Xie HY, Bai YR. Esophageal perforation during or after conformal radiotherapy for esophageal carcinoma. J Radiat Res (Tokyo). 2014 Sep 55(5):940-7.
15 Kawakami T, Tsushima T, Omae K, Ogawa H, Shirasu H, Kito Y, et al. Risk factors for esophageal fistula in thoracic esophageal squamous cell carcinoma invading adjacent organs treated with definitive chemoradiotherapy: a monocentric case-control study. BMC Cancer. 2018 May;18(1):573.

16 Taniguchi H, Yamazaki K, Boku N, Funakoshi T, Hamauchi S, Tsushima T, et al. Risk factors and clinical courses of chemoradiationrelated arterio-esophageal fistula in esophageal cancer patients with clinical invasion of the aorta. Int J Clin Oncol. 2011 Aug;16(4): 359-65.

17 Yamaguchi S, Ohguri T, Imada H, Yahara K, Moon SD, Higure A, et al. Multimodal approaches including three-dimensional conformal re-irradiation for recurrent or persistent esophageal cancer: preliminary results. J Radiat Res (Tokyo). 2011;52(6):812-20.

18 Xiao Z, Yang Z. Analysis of prognositic factors of radiotherapy for esophageal cancer perforation. Chin J Radiat Oncol. 1997;(4): 218-20.

19 Gabrail NY, Harrison BR, Sunwoo YC. Chemo-irradiation induced aortoesophageal fistula. J Surg Oncol. 1991 Nov;48(3):213-5.

20 Burt M, Diehl W, Martini N, Bains MS, Ginsberg RJ, McCormack PM, et al. Malignant esophagorespiratory fistula: management options and survival. Ann Thorac Surg. 1991 Dec;52(6):1222-8

21 Biancari F, D’Andrea V, Paone R, Di Marco C, Savino G, Koivukangas V, et al. Current treatment and outcome of esophageal perforations in adults: systematic review and metaanalysis of 75 studies. World J Surg. 2013 May;37(5):1051-9.

22 de Aquino JL, de Camargo JG, Cecchino GN, Pereira DA, Bento CA, Leandro-Merhi VA. Evaluation of urgent esophagectomy in esophageal perforation. Arq Bras Cir Dig. 2014 Nov-Dec;27(4):247-50

23 Nagaraja V, Cox MR, Eslick GD. Safety and efficacy of esophageal stents preceding or during neoadjuvant chemotherapy for esophageal cancer: a systematic review and metaanalysis. J Gastrointest Oncol. 2014 Apr;5(2): 119-26.

24 Schweigert M, Solymosi N, Dubecz A, Posada Gonzalez M, Stadlhuber RJ, Ofner D, et al. Emergency oesophagectomy for oesophageal perforation after chemoradiotherapy for oesophageal cancer. Ann R Coll Surg Engl. 2015 Mar;97(2):140-5.

25 Wells GA, Shea BJ, O'Connell D, Peterson JE, Welch V, Losos M, et al. The Newcastle-Ottawa Scale (NOS) for Assessing the Quality of Non-Randomized Studies in Meta-Analysis. Appl Eng Agric. 2012;18(6):727-34.

26 Higgins JP, Thompson SG, Deeks JJ, Altman DG. Measuring inconsistency in meta-analyses. BMJ. 2003 Sep;327(7414):557-60.
27 Egger M, Davey Smith G, Schneider M, Minder C. Bias in meta-analysis detected by a simple, graphical test measures of funnel plot asymmetry. BMJ. 1997;315(7109):629-34.

28 Hama Y, Uematsu M, Shioda A, Suda A, Aida S, Kusano S. Severe complications after hypofractionated high dose rate intracavitary brachytherapy following external beam irradiation for oesophageal carcinoma. $\mathrm{Br} \mathrm{J} \mathrm{Ra}$ diol. 2002 Mar;75(891):238-42.

29 Grazziotin Reisner R, Reisner ML, Ferreira MA, Rosa AA, Veras IM, Carneiro TM, et al. Measuring relief of dysphagia in locally advanced esophageal carcinoma patients submitted to high-dose-rate brachytherapy. Brachytherapy. 2015 Jan-Feb;14(1):84-90.

30 Ohtsu A, Boku N, Muro K, Chin K, Muto M Yoshida S, et al. Definitive chemoradiotherapy for T4 and/or M1 lymph node squamous cell carcinoma of the esophagus. J Clin Oncol. 1999 Sep;17(9):2915-21.

31 Kaneko K, Ito H, Konishi K, Kurahashi T, Ito T, Katagiri A, et al. Definitive chemoradiotherapy for patients with malignant stricture due to T3 or T4 squamous cell carcinoma of the oesophagus. Br J Cancer. 2003 Jan;88(1): 18-24.

32 Saito H, Sueyama H, Fukuda T, Ota K. Necrotising Candida oesophagitis after thoracic radiotherapy: significance of oesophageal wall oedema on CT. BMJ Case Rep. 2015 Jul; 2015:bcr2015210477.

33 Adelstein DJ, Rice TW, Rybicki LA, Larto MA, Ciezki J, Saxton J, et al. Does paclitaxel improve the chemoradiotherapy of locoregionally advanced esophageal cancer? A nonrandomized comparison with fluorouracilbased therapy. J Clin Oncol. 2000 May;18(10): 2032-9.

34 Nonoshita T, Sasaki T, Hirata H, Toh Y, Shioyama Y, Nakamura K, et al. High-doserate brachytherapy for previously irradiated patients with recurrent esophageal cancer. Radiat Med. 2007 Oct;25(8):373-7.

35 Nakamura T, Hayashi K, Ota M, Eguchi R, Ide $\mathrm{H}$, Takasaki K, et al. Salvage esophagectomy after definitive chemotherapy and radiotherapy for advanced esophageal cancer. Am J Surg. 2004 Sep;188(3):261-6.

36 Yano T, Muto M, Hattori S, Minashi K, Onozawa $M$, Nihei $K$, et al. Long-term results of salvage endoscopic mucosal resection in patients with local failure after definitive chemoradiotherapy for esophageal squamous cell carcinoma. Endoscopy. 2008 Sep;40(9):71721.

37 Santeufemia DA, Tumolo S, De Paoli A, Lo Re G, Boz G, Miolo GM, et al. Chemo/tomotherapy stereotactic body radiation therapy (chemo/SBRT) for the salvage treatment of esophageal carcinoma following trimodality therapy: a case report. Tumori. 2012 Sep-Oct;98 (5): $143 \mathrm{e}-5 \mathrm{e}$. 